\title{
KAVUKLU BÖLGESİ (ULUKIŞLA-NİĞDE) PALEOSEN-YAŞLI YASTIK LAVLARIN ALTERASYON MINERALOJISİ
}

\author{
Murat ÇÍFLİKLİ (ORCID: 0000-0003-4848-7965)* \\ Jeoloji Mühendisliği Bölümü, Mühendislik Fakültesi, Niğde Ömer Halisdemir Üniversitesi, Niğde, Türkiye
}

Geliş / Received: 16.11.2018

Kabul / Accepted: 20.12.2018

\begin{abstract}
ÖZ
Kavuklu (Ulukışla-Niğde) bölgesinde Paleosen yaşlı Ulukışla formasyonu içerisinde geniş yayılımlar sunan deniztabanı volkanizması ürünü olan bazaltik yastık lavlar yüzeylenmektedir. Yastık lav loblarının dış yüzeyinde yoğun, merkeze doğru azalan biçimde alterasyon gözlenmektedir. Bu çalışmada, yastık yapılı lav görünümlü bazaltik kayaçların mineralojik-petrografik özellikleri ve deniz suyu-volkanik kayaç etkileşiminden kaynaklanan alterasyon özelliklerinin incelenmesi amaçlanmıştır. Bu kapsamda, dokusal (optik ve elektron mikroskop), mineralojik (X-ışınları kııııımı-XRD) ve kimyasal (X-ısııları floresans spektrometresi-XRF) incelemeler gerçekleştirilmiştir. Optik mikroskop incelemelerine göre, alterasyonun yaygın olduğu örneklerde çatlak ve boşluk ve/veya gözenek dolgusu biçiminde çoğunlukla klorit, daha az oranda kısmen kloritleşmemiş biyotit olmak üzere fillosilikat mineralleri gözlenmiştir. Kloritler yer yer ferromagnezyen minerallerini tümüyle ornatmışlardır. Çatlak ve gözenek dolgusu biçiminde gözlenen karbonat ve kuvars mineralleri filosilikatlardan sonra gelişen son evre alterasyon ürünlerini temsil etmektedir. XRD kil fraksiyonu incelemeleri fillosilikat minerallerinin klorit, karışık tabakalı klorit-smektit (C-S, korensit) ve illit/mikalardan oluştuğunu göstermiştir. Fillosilikat birlikteliklerini klorit, klorit \pm C-S, klorit \pm illit, klorit $\pm \mathrm{C}$-S \pm illit oluşturmaktadır. Taramalı elektron mikroskop (SEM) verilerine göre kloritler 2-10 $\mu \mathrm{m}$ boyutlu, fleks biçimli topluluklar şeklinde gelişmiştir. Elde edilen bulgular, yastık yapılı bazaltların deniz tabanına yayılımı ve bunu izleyen dönemde volkanik kayaç-deniz suyu etkileşimi sonucu Fe ve $\mathrm{Mg}$ içeriği yüksek magmatik bileşenlerden itibaren $\mathrm{Fe}$ ve $\mathrm{Mg}$ içeriği yüksek (trioktahedral) fillosilikat minerallerinin geliştiğini göstermiştir. Daha sonraki evreyi temsil eden çatlak/gözenek dolgusu karbonat mineralleri bazaltik kayaçların denizel ortamda bulunmalarıyla ilişkili gözükmektedir.
\end{abstract}

Anahtar Kelimler: Yastık lav, bazaltik volkanizma, alterasyon, fillosilikat

\section{ALTERATION MINERALOGY OF PALEOCENE-AGED PILLOW LAVAS IN THE KAVUKLU REGION (ULUKIŞLA-NİĞDE)}

\begin{abstract}
Within the Paleocene Ulukışla formation in the Kavuklu (Ulukışla-Niğde) region, basaltic rocks which are products of pillow lavas that formed during marine volcanism are widely exposed. In the pillow lava lobes, an intense alteration is usually observed on the outer surface with a decreasing alteration trend towards the core. In this study, mineralogical-petrographic properties of basaltic rocks with pillow-shaped lava-like appearance and alteration properties of volcanic rocks influenced by seawater interaction were investigated. The textural properties were determined using optical and scanning electron microscope (SEM), mineralogical (X-ray diffraction-XRD), and chemical (X-ray fluorescence spectrometry-XRF). According to the optical microscope studies, phyllosilicate occurrences, mostly chlorite and less biotite, in the form of cracks and voids and/or pore fills were observed in the
\end{abstract}

\footnotetext{
${ }^{*}$ Corresponding author / Sorumlu yazar. Tel.:+90 3882254006 ; e-mail / e-posta: mciflikli@ ohu.edu.tr
} 


\section{M. ÇIFLIKLLI}

samples where alteration was common. Chlorites have completely substituted ferromagnesian minerals in places. The carbonate and quartz minerals observed in the form of cracks and pore fills represent the last phase of alteration products that developed after phyllosilicates. XRD clay fraction studies have shown that phyllosilicate minerals are composed of chlorite, mixed bedded chlorite-smectite (C-S, corrensite), and illite/mica. Phyllosilicate associations consist of chlorite, chlorite $\pm \mathrm{C}-\mathrm{S}$, chlorite \pm illite, and chlorite $\pm \mathrm{C}-\mathrm{S} \pm$ illite. SEM results revealed that chlorites were characterized by $2-10 \mu \mathrm{m}$ size, flakes shaped communities. The findings showed that the pillowstructured basalts developed at the seafloor and the subsequent Fe-Mg contents of the marine volcanic rocks developed from the high magmatic components of $\mathrm{Fe}$ and $\mathrm{Mg}$ (trioctahedral) of the phyllosilicate minerals. The fracture / pore-filling carbonate minerals representing the later stage seem to be related to the presence of basaltic rocks in the marine environment.

Keywords: pillow lava, basaltic volcanism, alteration, phyllosilicate

\section{GíRİs}

Niğde-Ulukışla-Çamardı bölgesinin jeolojisini ayrıntılı olarak ilk kez çalışmış olan [1]., yapmış olduğu araştırmalarda birimlerin adlandırılmasını ve çökelme ortamını ortaya koymaya çalışmıştır. Yine aynı bölge ve civarında [2] tarafından yapılan çalışmalarında Bolkardağları ve çevresinin genel jeolojisini ve stratigrafisini ortaya koymuştur. Söz konusu çalışmada Bolkardağlarının kuzeyinde Ereğli-Ulukışla havzası, güney eteklerinde Ayrancı havzası olmak üzere iki farklı çökelme havzası ayırtlanmıştır. Ereğli-Ulukışla havzasının Geç KretasePaleosen yaşlı formasyonlarının filiş evresini temsil ettiğini belirtmiştir.

Ulukışla ile Çamardı arasında yüzlek veren volkanizma Paleosen'den Orta Eosen'e kadar etkili olmuştur. Volkanitler sahada yaygın olarak aglomera, yastık lav, tüf, kubbe, dayk ve akıntı breşi şeklinde görülürler ve yer yer volkanosedimanter özellik gösterirler. Sokulum kayaçları özellikle Ulukışla çevresinde yaygındır. Jeokimyasal ve jeolojik verilere göre Geç Kretase-Orta Eosen yaş aralığında bölgedeki okyanus içerisinde gelişen, kuzeye dalımlı bir yitim zonunun, incelenen kayaçların oluşumunu sağladığını düşünmektedir. Ulukışla formasyonunun belirli yerlerinde alınan örnekler üzerinde yaptıkları analizlerde bileşimlerine göre bazalt, andezit ve riyolitten oluşan kayaçların alkali (şoşonitik) ve kısmen de subalkali olduklarını; ana ve bazı iz elementlerine göre de volkanik yay ürünü olduklarını belirtilmişitir [3].

\section{GENEL JEOLOJI}

Ereğli-Ulukışla Havzası'nın doğu sınırını Aladağlar ve Ecemiş fayı, batı sınırını, Bor hattında görülen Niğde masifi, güney sınırını ise Bolkar dağları oluşturmaktadır [2]. Bölge Tersiyer başında, içinde volkanik bir ada yayının gelişmekte olduğu kapanan bir okyanus durumundadır. Kapanma, kuzeyden güneye ilerleyen kıta/adayayı/kıta çarpışması şeklinde gelişmiştir [4]. Okyanusal çukurluk içinde yer alan Ulukışla ve çevresinde derin denizel paleocoğrafik koşullar egemendir. Geç Kretase'de bölge güneyine bir ofiyolitik yerleşim söz konusudur. Bu yerleşim dalma-batma zonunun işlevinin sona ermesiyle oluşmuştur ve bu sebeple bir magmatik etkinlik söz konusudur. Dalan tablanın hareketini Paleosen boyunca sürdürmesi ve dolayısıyla kısmi ergimesi sonucu, Ulukışla çevresinde doğu-batı doğrultulu bir adayayı gelişmiştir [4] (Şekil 1).

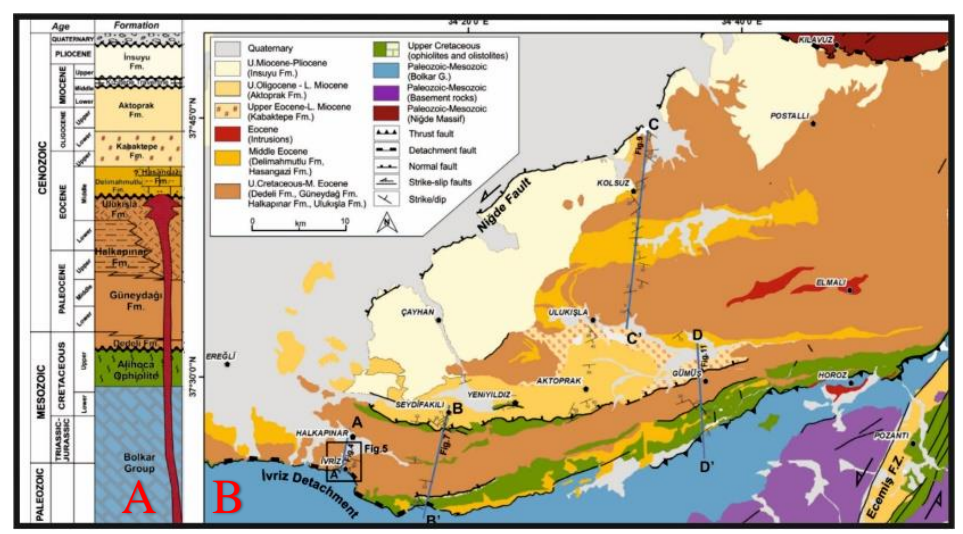

Şekil 1. Ulukışla Basenine ait jeolojik harita ve bölgenin stratigrafik istifi (A-B:[9]'den değiştirilerek alınmıştır). 
Ulukışla Formasyonu (KTu); ilk olarak [2] tarafindan adlandırılmıştır. Ulukışla formasyonunun çoğunluğu aglomera, andezitik lav akıntıları, tüfler, tüfitler, volkanik breşler ve yastık lavlardan oluşur. Bütün bu volkanik malzeme türbiditik kumtaşı, kayma çökelleri ve ender olarak kireçtaşı ve şeyl ile ara tabakalıdır. Birimin yaşı Geç Kretase-Erken Eosen olarak belirlenmiştir [5]. [4]'a göre; Ereğli-Ulukışla bölgesinin temelini Ulukışla grubu oluşturur. İçerisinde sığ-derin denizel tortullar, denizaltı volkanikleri ve bunlar içine zaman zaman dayk ya da sığ sokulumların olduğunu belirtmiştir. Araştırıcı Ulukışla grubunu Sansartepe formasyonu, Serenkaya formasyonu, Başmakçı kireçtaşı, Cehritepe siyeniti, Köyderesi trakiti, Karatepe kireçtaşı, Güney formasyonu, Tayhacı andeziti ve Dikmendere trakitleri birimlerine ayırmıştır (Şekil 1). Birimin Halkapınar formasyonu ile olan dokanağ yanal ve düşey geçişlidir. Ulukışla formasyonu Hasangazi formasyonu ve Güney formasyonu ile de yanal ve düşey geçişli bir görünüm sergilediği birimin yayıldığı yerlerde görülür. Birimin karışık magmatik-sedimanter ilişkileri nedeniyle formasyonun kalınlığı tam olarak bilinmemektedir.

İnceleme alanında çökel kayaların temelini Geç Permiyen-Geç Triyas yaşlı Bolkar grubu metamorfikleriyle [6] Üst Kretase yaşlı ofiyolitik melanj [7], [2] ,[8] oluşturmaktadır.

Ulukışla formasyonu, çoğunluğu aglomera, andezitik lav akıntıları, tüfler, tüfitler, volkanik breşler ve yastık lavlardan oluşur. Bütün bu volkanik malzeme türbiditik kumtaşı, kayma (slump) çökelleri, ender olarak kireçtaşı ve şeyl ile ara tabakalıdır. Bunlar üzerinde Geç Paleosen-Erken Eosen yaşlı Hasangazi formasyonu yine yanal ve düşey geçişli olarak Ulukışla formasyonu üzerinde yer alır [9], [8] (Şekil 1).

\section{METERYAL ve YÖNTEM}

Niğde güney batısında yer alan Üst Paleosen-Eosen yaşlı yastık yapılı lav görünümlü bazaltik kayaçlardan toplam 40 örnek alınmıştır. Örnekler üzerinde sırasıyla optik (OM) ve taramalı elektron mikroskobu (SEM), X-1şınları difraksiyonu (XRD)-tüm kayaç (TK) ve kil fraksiyonu (KF) incelemeleri yapılmıştır. OM incelemeleri alttan aydınlatmalı binoküler polarizan mikroskopta, XRD incelemeleri ve SEM incelemeleri Philips Panalytical EMPYREAN cihazda NÖHÜ Merkezi Araştırma Labaratuvarı Analiz Biriminde yapılmıştır, OM incelemeleri hazırlanan incekesitlerde Nikon ECLIPSE E4O0 marka binoküler alttan aydınlatmalı polarizan mikroskopta yapılmıştır.

\section{BULGULAR ve TATIŞMALAR}

\subsection{Mineraloji-Petrografi}

Bölgede yayılım gösteren Üst Paleosen-Eosen yaşlı yastık yapılı lavların optik mikroskop incelemelerinde porfirik/camsı porfirik doku gösteren kayaçta yine hamur içerisinde pilajiyoklas ve tremolit-aktinolit çubukları mikrolitler şeklinde, bazende fenokristaller şeklinde izlenmektedir. Plajiyoklas mineralleri genellikle serisitleşmiş, ferrromagnezyen minerallerde ise yer yer kenardan itibaren oksitlenme ve opasitleşmeler belirlenmiştir. Ortopiroksen (enstatit) ve çoğunlukla klinopiroksen (diyopsit ) mineralleri görülmekte ve olivin fenokristalleri gözlenmektedir (Şekil 2).

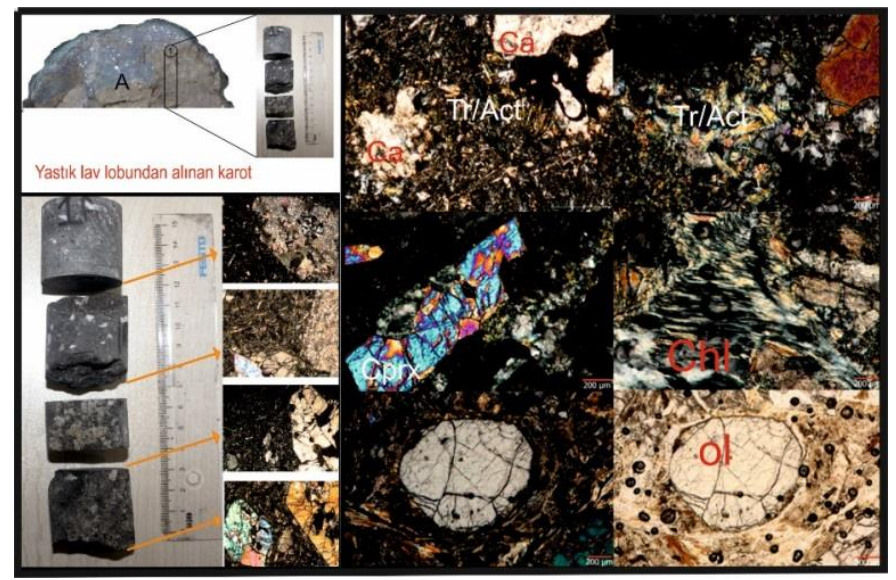

Şekil 2. Çalışma alanına ait karot ve normal numunelerin incekesit görüntüleri (Ol: olivin, Chl: Klorit, Cprx: Klinopiroksen, Ca: kalsit, Tr:Tiremolit, Act: Aktinolit). 


\section{M. ÇIFLIKLI}

Optik mikroskop incelemelerine göre, alterasyonun yaygın olduğu örneklerde çatlak ve boşluk ve/veya gözenek dolgusu biçiminde çoğunlukla klorit, daha az da biyotit olmak üzere fillosilikat oluşumları gözlenmiştir. Kloritler yer yer ferromagnezyen minerallerini tümüyle ornatmışlardır. Çatlak ve gözenek dolgusu biçiminde gözlenen karbonat ve kuvars mineralleri filosilikatlardan sonra gelişen son evre alterasyon ürünlerini temsil etmektedir (Şekil 2).

\subsection{XRD Analiz Sonuçları}

Üst Paleosen-Eosen yaşlı yastık yapılı lavların temsil eden örneklerde XRD tümkayaç ve kil fraksiyonu incelemeleri sonucunda fillosilikat minerallerinin klorit, karışık tabakalı klorit-smektit (C-S, korensit) ve illit/mikalardan oluştuğunu göstermiştir. Fillosilikat birlikteliklerini klorit, klorit $\pm \mathrm{C}$-S, klorit \pm illit, klorit $\pm \mathrm{C}$-S \pm illit oluşturmaktadır. Örneklerde klorit 14.1 $\AA, 7.2 \AA, 4.73 \AA$ ve $3.54 \AA$ da ki pikleri sırasılyla (001), (002), (003), (004) yansımalarına karşılık gelmektedir. $7 \AA$ daki klorit pikinin şiddetli olması Fe'ce zengin (şamozitik) olduğuna işaret etmektedir. Etilen glikollü (EG) çekimde $14 \AA$ ve $7 \AA$ piklerinin solunda ortaya çıkan pikler C-S aratabakalı faza işaret etmektedir (Şekil 3).

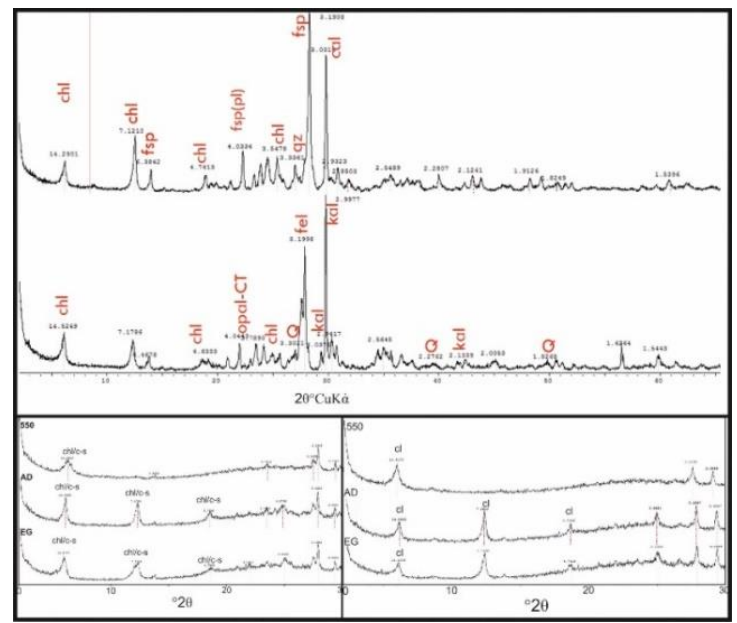

Şekil 3. Taramalı Elektron mikroskopta incelenen örneklere ait görüntü (C-S: korensit, chl: Klorit, Q: kuvars, Kal: Kalsit, Fel: Feldispat, Opal-CT: kristobalit/Tridimit ).

\subsection{SEM Analiz Sonuçları}

Yapılan XRD analiz değerlendirmeleri sonucunda Elektron mikroskop görüntülemesi yapılan örneklerde Peteksi biçimli simektitler boşluk/gözenek dolgusu şeklinde çözeltilerden itibaren doğrudan (neoformasyon) oluşmuştur. Bıçaksı-levhamsı kloritler ferromagnezyen minerallerden itibaren bozuşma (dönüşüm) ürünü olarak oluşmuştur. 


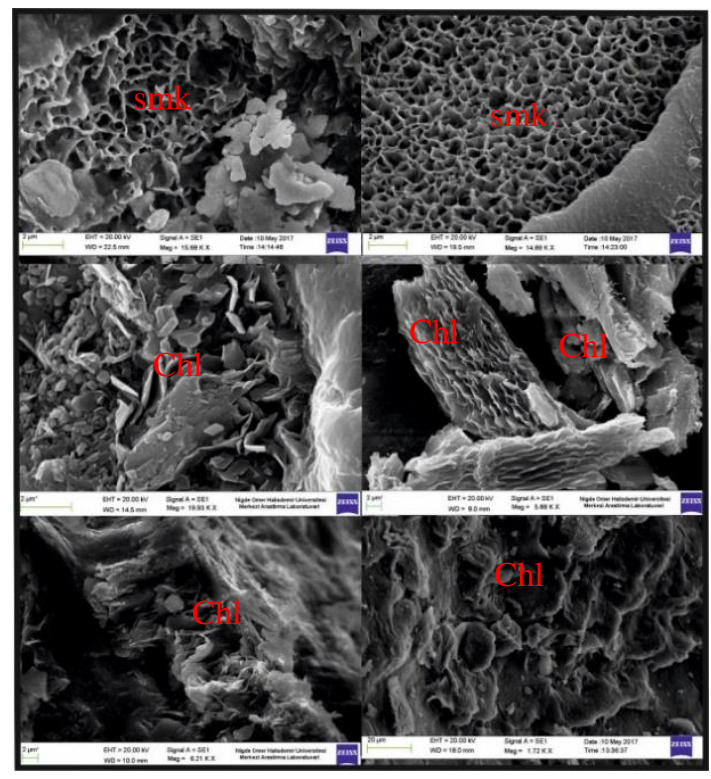

Şekil 4. Ulukışla formasyonuna ait birimlerinde klorit ve eşlikeden minerallerin SEM görüntüleri

\subsection{Jeokimyasal Analiz Sonuçları}

Ulukışla formasyonuna ait birimlerden alınan örneklerin ana element içerikleri incelendiğinde literatürde yer alan önceki çalışmalarla benzerlik sunmaktadır. Yapılan analizlerde $\mathrm{Fe}$ ve $\mathrm{Mg}$ değerlerinin yüksekliği dikkati çekmekte. Analizi yapılan örneklerin AFM ve toplam alkali silis (TAS) diyagramlarında bir kısmının Toleyitik seriye bir kısmının ise Kalkalkali seriye düştüğü ve bileşim olarak örneklerin çoğunluğunun bazaltik andezit bileşimli olduğu görülmektedir (Şekil 4).

Yastık yapılı bazaltların deniz tabanına yayılımı ve bunu izleyen dönemde volkanik kayaç-deniz suyu etkileşimi sonucu ferromagnezyen içeriği yüksek magmatik bileşenlerden itibaren Fe ve Mg içeriği yüksek alterasyon minerallerin geliştiğini göstermiştir.

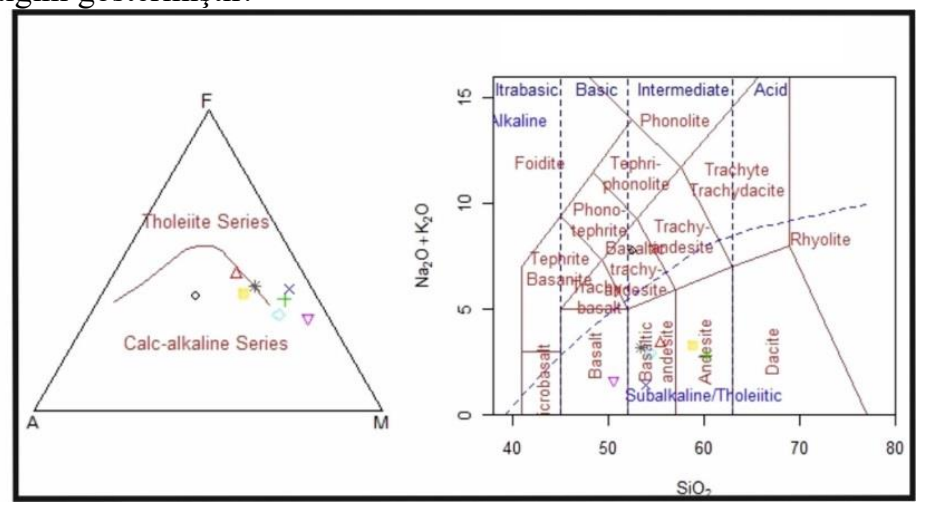

Şekil 4. Ana element analiz sonuçlarının AFM ve TAS diyagramları.

\section{SONUÇLAR}

Yastık yapılı bazaltların deniz tabanına yayılımı ve bunu izleyen dönemde volkanik kayaç-deniz suyu etkileşimi sonucu Fe ve Mg içeriği yüksek magmatik bileşenlerden itibaren Fe ve Mg içeriği yüksek (trioktahedral) fillosilikat minerallerinin (klorit, klorit-simektit) geliştiğini göstermiştir. Bu ikincil mineral oluşumları incekesit görüntülerinde de kloritleşme gibi diğer alterasyon minerallerinin varlı̆̆ıyla net olarak izlenmektedir.

Daha sonraki evreyi temsil eden çatlak/gözenek dolgusu karbonat mineralleri bazaltik kayaçların denizel ortamda bulunmalarıyla ilişkili gözükmektedir. Ortamdaki alterasyonla oluşan klorit minerallerine yer yer simektit dolguları karbonat mineralleri eşlik etmektedir. 


\section{M. ÇIFLIKLLI}

\section{TEŞEKKÜR}

Bu çalışma Niğde Ömer Halisdemir Üniversitesi Bilimsel Araştırmalar birimi tarafından FEB2014/09BAGEP no’lu projeyle desteklenmişitir. Yazar çalışmaları sırasında desteklerinden dolayı Niğde Ömer Halisdemir Üniversitesi Merkezi Araştırma Laboratuvarı Analiz Birimine teşekkürlerini sunar. Analizlerin yapılmasında emeği geçen uzman Nebi YELEĞEN ve uzman Esra KILAVUZ’a ve makalenin son haline gelmesinde katk1, görüş ve önerilerinden dolayı Prof.Dr.Ömer BOZKAYA'ya ve yayını inceleyen hakemlere sonsuz teşekkürlerini sunar.

\section{KAYNAKLAR}

[1] OKAY, A.C.“Nigde-Çamardı ve Ulukısla arasındaki bölgenin jeolojisi, Ank.”, MTA Derl. no: 2381, 1955

[2] DEMIRTAŞLI, E., BİLGIN, A.Z., ERENLER, F., IŞIKLAR, S., ŞANLI, N.Y., SELIM, M. ve TURHAN, N. "Bolkardaglarının Jeolojisi" Cumhuriyetin 50. y1lı Yerbilimleri Kongresi,Tebligler, MTA Yayını, Ankara, 608 s, 1973.

[3] BAS, H. "Ulukısla-Çamardı (Nigde) Volkanitlerinin bazı petrolojik ve jeokimyasal özellikleri” TMMOB Jeoloji müh. Odası yayını, Sayı:26., 1986.

[4] OKTAY, F.Y. "Ulukısla ve çevresinin stratigrafisi ve jeolojik evrimi” TJK Bülteni, 25, 15-23, 1982.

[5] DELlAlOGLU, A.A. ve Aksu, R. "Eregli (Konya)-Ulukısla-Çiftehan-Çamardı(Nigde) dolayının jeolojisi ve petrol olanakları” TPAO. Rapor No.2205, 1986.

[6] BLUMENTAL, M.M. "Yüksek Bolkardagının kuzey kenar bölgelerinin ve batı uzantılarının jeolojisi" MTA yayını, Seri D, No. 7, Ankara, 153 s., 1956.

[7] KETIN, İ. ve AKARSU, I. "Ulukısla Tersiyer Havzasının jeolojik etüdü hakkında rapor" TPAO, No: 339, 1965.

[8] DURSUN, A.İ., "Ereğli-Ulukışla Havzası Ulukışla Formasyonunun (Ulukışla ve Çevresi) Petrol Hazne Kaya Özellikleri” Ankara Üniversitesi Fen Bilimleri Enstitüsü Yüksek Lisans Tezi, 682006. (yayımlanmamış).

[9] SEYİTOĞLU, G.,IŞIK, V., GÜRBÜZ, E. ve GÜRBÜZ, A. "The discovery of a low-angle normal fault in the Taurus Mountains: the İvriz detachment and implications concerning the Cenozoic geology of southern Turkey", Turkish Journal of Earth Sciences,TÜBİTAK. 26: 189-205, (2017). 